\title{
Monitorización de la microcirculación en cirugía cardíaca
}

\section{Microcirculation monitoring in cardiac surgery}

\author{
Mariana Monteiro MD. ${ }^{1}$, Jimena Calviño MD. ${ }^{1}$, Eduardo Kohn MD. ${ }^{1}$, Laura Illescas MD. ${ }^{1}$, Juan Pablo Bouchacourt PhD. ${ }^{\text {, }}$ \\ Leticia Turconi MD. ${ }^{1}$, Leandro Gonzales MD. ${ }^{1}$, Juan Riva MD. ${ }^{1, *}$ \\ 1 Departamento de Anestesiología. Facultad de Medicina. Universidad de la República. Uruguay.
}

Fecha de recepción: 05 de septiembre de 2021 / Fecha de aceptación: 12 de septiembre de 2021

\begin{abstract}
This article presents our perspective about the limitations in the monitoring of microcirculation during cardiac surgery. The strategies in the perioperative management of these patients are based in the systemic hemodynamic variables. However, some patients have a worse outcome, which could be due to microcirculatory alterations. We present the types of microcirculation alterations associated to cardiac surgery itself and cardiopulmonary bypass. We reviewed the concept of hemodynamic coherence, which implies that for a treatment to be effective, there must be coherence between macro and micro hemodynamics, consequently, monitoring the microcirculation becomes relevant. The article emphasizes the methods currently used to monitor the peripheral perfusion: a) indirect tissue oxygenation measurements: oxygen saturation in venous blood, blood lactate level and measurements derived from $\mathrm{CO}_{2} ;$ b) video microscopy techniques, and c) muscle tissue saturation $\left(\mathrm{StO}_{2}\right)$ with the near infrared spectroscopy technique (NIRS) associated at the vascular occlusion test (VOT). In each of them, we highlight their importance and how the alterations caused by the surgery itself and/or the cardiopulmonary bypass can affect these measures. Thus these alterations must be known when making therapeutic decisions based on them.
\end{abstract}

Key words: Microvessel, microcirculation, tissue perfusion, cardiac surgery.

\section{RESUMEN}

Este artículo es la opinión de nuestro grupo de trabajo acerca de las limitaciones que se presentan en la monitorización de la microcirculación durante la cirugía cardíaca. Las principales estrategias en el manejo perioperatorio de estos pacientes se centran en la monitorización y optimización hemodinámica sistémica. En ocasiones, a pesar de alcanzar estos objetivos los pacientes presentan una mala evolución, lo que podría deberse a alteraciones microcirculatorias. Definimos la microcirculación y presentamos los principales determinantes de estas alteraciones vinculados a la cirugía cardíaca en sí misma y al bypass cardiopulmonar. Planteamos el concepto de coherencia hemodinámica lo cual implica que para que un tratamiento sea efectivo debe existir una coherencia entre la macro y microhemodinamia, lo que explica la relevancia de la monitorización a nivel de la microcirculación. El artículo enfatiza en los métodos utilizados actualmente: a) medidas indirectas de oxigenación tisular: saturación de oxígeno en sangre venosa, lactato sanguíneo y las medidas derivadas del $\mathrm{CO}_{2} ;$ b) técnicas de microvideoscopía y c) saturación tisular de oxígeno $\left(\mathrm{StO}_{2}\right)$ con el test de oclusión vascular. En cada uno de ellos señalamos su importancia y cómo las alteraciones provocadas por la propia cirugía y/o la circulación extracorpórea pueden afectar estas medidas, las cuales deben conocerse al momento de tomar decisiones terapéuticas basadas en ellas.

Palabras clave: Microcirculación, perfusión tisular, cirugía cardiaca. 


\section{Introducción}

a cirugía cardíaca (CC) sigue siendo un procedimiento de alto riesgo debido tanto al procedimiento en sí mismo, como a las características de los pacientes que pueden acceder a ella. Una parte de los progresos ha sido el desarrollo de guías de tratamientos centrados en mejorar las condiciones hemodinámicas y de oxigenación. Dentro de ellos se destaca el "tratamiento guiado por objetivos" (TGO) cuya hipótesis es que mejorando el gasto cardíaco (GC), en base a un protocolo con inotrópicos y/o fluidos sería posible evitar la "deuda de oxígeno" que se genera y de esta forma reducir la mortalidad y morbilidad en el posoperatorio. Esta presentó resultados promisorios tanto en cirugía abdominal de alto riesgo[1] como en CC con circulación extracorpórea (CEC)[2]. No obstante estudios posteriores han mostrado resultados contradictorios que se atribuyen a sesgos vinculados a la inclusión de pacientes de bajo riesgo, la necesidad de poblaciones mayores y bien definidas en el contexto específico de la CC[3] y la utilidad de los marcadores de perfusión tisular como parte de esos objetivos[4]. Se ha sugerido que una de las limitaciones de esta estrategia es que la optimización de los parámetros hemodinámicos sistémicos no asegura una adecuada distribución a nivel microcirculatorio, lugar donde sucede la oxigenación tisular. En el paciente quirúrgico esto quiere decir que el TGO será útil en la medida que la falla orgánica no esté establecida y la "deuda de oxígeno" pueda ser compensada, por tanto, los mecanismos de regulación de la microcirculación deben estar intactos y ser capaces de detectar y regular el transporte de oxígeno a los diversos tejidos[5]. Una comprensión de lo que sucede a este nivel redundará en una mejor utilización de los recursos tanto de monitorización como de posibles tratamientos. En este artículo nos proponemos analizar las posibles alteraciones de la microcirculación y su monitorización en cirugía cardíaca.

\section{Definición de microcirculación}

La microcirculación consiste en una compleja red de vasos sanguíneos (< $100 \mu \mathrm{m}$ de diámetro) que incluye arteriolas, capilares y vénulas; siendo el destino final del transporte de oxígeno a las células parenquimatosas necesario para mantener la integridad estructural y funcional celular. Para cumplir con este objetivo debe existir un preciso control de la distribución del flujo sanguíneo de acuerdo con los requerimientos metabólicos y regionales en cada momento.

\section{Regulación de la microcirculación}

La circulación del músculo esquelético ha sido una de las más estudiadas dada la gran variación del flujo que se puede producir en un muy corto período de tiempo[6]. Desde un punto de vista funcional, la organización y el control de la perfusión de los capilares se define como la unidad microvascular (UM). Esta consiste en una arteriola terminal (AT) que da lugar a un grupo de entre 10-20 capilares de 500 a $1.000 \mu \mathrm{m}$ de largo que se distribuyen en ambas direcciones y terminan en una vena colectora. A su vez cada AT tiene un vaso también terminal que la alimenta y que llamaremos vaso de alimentación (VA) (Figura 1A). La regulación del flujo puede plantearse de la siguiente forma: el VA es la llave de control, es decir será el determinante de la distribución del flujo entre las AT (vasos de resistencia). Cuando esta se dilata reclutará los diferentes capilares que dependen de ella y el flujo capilar aumentaría. No obstante, el orifico de entrada al capilar se comporta como un esfínter pasivo (funcional) que se dilata para dar entrada al flujo sanguíneo, con lo cual puede existir una dilatación arteriolar sin que esto determine flujo a nivel capilar, en la medida que no exista una diferencia de presión necesaria para que ello ocurra. De esta forma la perfusión capilar dependerá entonces de factores físicos y hemodinámicos de la arteriola terminal y de la resistencia al flujo generada por el esfínter capilar. En reposo, el tono vasomotor refleja la interacción entre por un lado la contracción arteriolar en respuesta a la presión arterial (respuesta miogénica) y por otro, la vasodilatación provocada por el óxido nítrico local (NO) liberado desde el endotelio vascular por estímulo de las fuerzas de cizallamiento que provoca el flujo sanguíneo (Figura 1B).

\section{Propagación local y regional de las señales}

Frente a un aumento de las demandas metabólicas tisulares el primer nivel de respuesta será en el "esfínter" funcional precapilar que regulará la cantidad de capilares perfundidos determinando entonces el área de superficie del intercambio. A medida que la actividad metabólica se incrementa, el lugar de regulación del suministro de flujo sanguíneo se desplazará desde los esfínteres precapilares a los vasos de resistencia. Sin

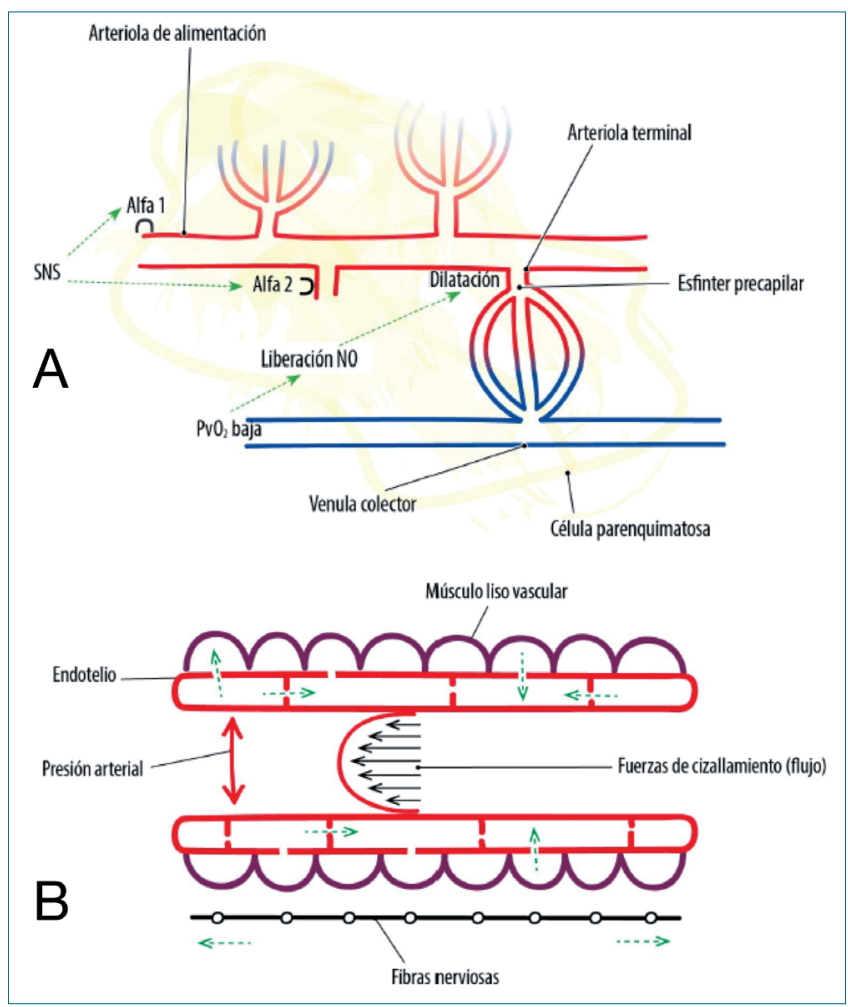

Figura 1. A. Esquema de la unidad microvascular. En ella se muestra los diferentes componentes anatómicos, así como los principales mecanismos de regulación regional y sistémico. SNS: sistema nervioso simpático; B. Se muestran los principales factores hemodinámicos, físicos y neurológicos que participan en el flujo a nivel periférico. Las flechas verdes punteadas indican la propagación de las señales. 
embargo, la vasodilatación abarca más de lo que esta red de resistencia puede explicar. Las vénulas corren paralelas a las arteriolas a través de las respectivas redes, por lo tanto, la microcirculación venosa está en una posición óptima para monitorizar el estado metabólico del tejido y, por tanto, modular el tono arteriolar. Las sustancias vaso activas liberadas desde las células generan un gradiente entre la sangre venosa y la arteriolar y por tanto una "contracorriente" desde la primera (vía el espacio extracelular) hacia las arteriolas cercanas. Por otra parte, las células endoteliales venulares pueden responder al stress sobre su pared liberando autacoides (óxido nítrico (ON)) que actúan sobre las células del músculo liso de las arteriolas cercanas. Frente a una $\mathrm{PO}_{2}$ baja se libera $\mathrm{ON}$ desde la hemoglobina a nivel venular el cual llegará ("contracorriente") a nivel arteriolar provocando la dilatación y aumento del flujo capilar (Figura 1 A). De manera complementaria, la capacidad de los glóbulos rojos para liberar ATP puede activar receptores purinérgicos en las células endoteliales venulares para producir dilatación arteriolar.

\section{Propagación a distancia de la respuesta vasomotora}

La respuesta vasodilatadora excede al lugar donde se produce el estímulo y puede ser explicada por diferentes mecanismos. Uno de ellos es que los estímulos se propagan bidireccionalmente por reflejos axonales de pequeñas fibras nerviosas presentes en el lugar donde se inicia el estímulo. Otro posible mecanismo es la conducción a través de las fibras del músculo liso de los propios vasos, la cual sería independiente de los cambios de flujo sanguíneo, presión arterial y actividad neuronal. El mecanismo íntimo sería un acoplamiento célula-célula, a través de los canales de unión a nivel endotelial tanto homocelular como heterocelular (mio-endotelial) (Figura 1B). Esta conducción estaría modulada por isquemia, presión transmural, histamina y la actividad de los nervios simpáticos.

¿Cómo participa el sistema nervioso autónomo en esta regulación? Existe una regulación diferencial de los segmentos distales y proximales de los vasos de resistencia, siendo los primeros más sensibles a las demandas metabólicas y, por tanto, capaces de anular los efectos de la actividad del nervio simpático (Figura 1A). Esta capacidad aumenta al mismo tiempo que la vasoconstricción se mantiene en las arteriolas proximales. Esto podría ser posible por una distribución diferencial de los adrenorreceptores $\alpha 1$ (vasodilatadores) y $\alpha 2$ (vasodilatadores) en las células del músculo liso arteriolar.

\section{Alteraciones de la microcirculación}

El conocimiento de la fisiopatología de la microcirculación ha progresado con la incorporación del método de visualización directa de la microcirculación sublingual con microscopios vitales portátiles. Basado en esta metodología Can Ince[5] plantea cuatro modelos de alteraciones a este nivel tomando en cuenta la densidad capilar funcional (DCF), es decir, la cantidad de capilares efectivamente perfundidos y por tanto capaces de entregar oxígeno a nivel periférico y remover el anhídrido carbónico. De forma complementaria Koning y cols.[7] plantean que desde el punto de vista fisiopatológico existen dos determinantes del aporte de oxígeno capaces de explicar las alteraciones microcirculatorias que ocurren en la CC: a) determinantes difusivos que corresponde al gradiente pasivo a través de barreras tisulares (área de intercambio) y b) determinantes convectivos que refieren a los procesos que generan y modulan el flujo localmente (hematocrito y flujo).

Integrando ambos conceptos podemos definir las siguientes alteraciones en CC.

1- Tipo I. En las que existe una heterogeneidad en la DCF, es decir, que alternan a nivel periférico capilares obstruidos junto a otros con pasaje libre de glóbulos rojos. La obstrucción de los capilares determinará entonces alteraciones difusivas por pérdida de gradiente, así como convectivas por alteraciones del flujo capilar. Las causas son diversas: obstrucciones de los eritrocitos por disfunción de las células endoteliales, alteraciones reológicas y/o pérdida o alteración del tono vasomotor. En el contexto de la CC estas alteraciones se describen por la exposición a los diferentes componentes del circuito de CEC.

2- Tipo II. La presencia de hemodilución causada por las soluciones de cebado, cardioplejía y administración de fluidos en el peroperatorio. Esta explica la anemia con la consecuente disminución de la disponibilidad de $\mathrm{O}_{2}$ y la disminución de la viscosidad sanguínea alterando las fuerzas de cizallamiento, componente necesario para la vasorregulación dependiente del flujo a nivel microcirculatorio.

3- Tipo III. Vasoconstricción/taponamiento. Tanto la vasoconstricción arteriolar con la consiguiente isquemia como la obstrucción venosa debido a aumento de la presión venosa llevando a estasis sanguíneo, provocan disminución de la oxigenación. De esta forma se alteran ambos componentes, el difusivo (alteración de los gradientes en un área determinada) y el convectivo (alteraciones del flujo). Este mecanismo se ha planteado por el uso de drogas y/o estrategias de reposición basados en valores de presión venosa central, los cuales son utilizados habitualmente en procedimientos de CC.

4- Tipo IV. Edema causado por el daño a nivel endotelial con aumento de la permeabilidad vascular, con una severa alteración del componente difusivo en el aporte de oxígeno. La CC y en especial la CEC han sido señalados como posibles causas de alteraciones a este nivel como consecuencia de la reacción inflamatoria sistémica que ellas provocan[8].

Estos perfiles microcirculatorios pueden presentarse aislados o combinados en diferentes momentos de la cirugía, incluso sea esta con o sin CEC. Por otro lado, esto nos explica las posibles deficiencias de los TGO convencionales para lograr la perfusión de órganos y la oxigenación de los tejidos en diferentes condiciones y por qué es importante monitorear la microcirculación[5]. Para que la corrección de variables sistémicas sea efectiva, debe existir coherencia entre la macrocirculación y la microcirculación. En condiciones de inflamación sistémica se pierden la regulación vascular y los mecanismos compensatorios necesarios para mantener esta coherencia hemodinámica. Es entonces razonable suponer que un TGO será deletéreo en un perfil microcirculatorio donde predominen el aumento de la heterogeneidad y edema micorcirculatorio.

\section{Relación entre la macro y microcirculación}

Los TGO habituales incluyen la utilización de valores hemodinámcos normales e incluso supranormales[10], los cuales han 
sido cuestionados ya que pueden ser el verdadero problema si la microcirculación se vuelve incapaz de regular el flujo y el transporte de $\mathrm{O}_{2}$ y nutrientes a los tejidos.

Dentro de ciertos rangos de presión arterial media (PAM) y gasto cardíaco (GC), el flujo microcirculatorio es relativamente independiente de estos[11]. Existe un nivel crítico de PAM, por debajo del cual la microcirculación se vuelve dependiente de la misma, modificaciones entre 60-90 mmhg no se acomapaña de cambios de flujo en la microcirculación[12],[13]. En los pacientes críticos además de las alteraciones hemodinámicas sistémicas observadas, son frecuentes las alteraciones en la microcirculación. Por tanto, la coherencia entre la macro y la microhemodinamia implicará que la corrección de las variables sistémicas es efectiva sí corrige la perfusión y oxigenación a nivel microcirculatorio. El período perioperatorio se caracteriza por una respuesta de stress expresada en diferentes sistemas y que asocia aumento del consumo de $\mathrm{O}_{2}\left(\mathrm{VO}_{2}\right)$ tisular, que de no corresponderse con una adecuada disponibilidad de $\mathrm{O}_{2}\left(\mathrm{DO}_{2}\right)$, dará inicio al déficit en la oxigenación y perfusión tisular con la consiguiente disfunción orgánica y aumento de la morbimortalidad[14]. Cuando la mejoría de las variables macro hemodinámicas no se corresponden con las de perfusión periférica debemos plantear que se ha perdido esta "coherencia hemodinámica". Esta situación podría ser producto de uno o más de los modelos de alteraciones de la microcirculación que fueron propuestos: disminución de la sensibilidad de la microcirculación a sustancias vasoactivas, la liberación de mediadores inflamatorios, destrucción del glicocalis y activación de la coagulación.

La efectividad del TGO es tiempo dependiente y sus efectos positivos podrán evidenciarse cuando la disfunción orgánica no se haya establecido[15]. En pacientes en shock luego de la circulación extracorpórea, las alteraciones de la microcirculación son independientes de la PAM, lo que sería consecuencia de los fenómenos inflamatorios que tienen lugar[16]. La no respuesta a un TGO dependerá también de las características del procedimiento quirúrgico, del daño asociado y de la reserva fisiológica basal del paciente[17]. Como consecuencia, es necesario considerar la monitorización de la microcirculación con el objetivo de identificar esta pérdida de coherencia y sus mecanismos subyacentes a fin de implementar estrategias terapéuticas específicas en este sentido[18].

\section{Técnicas de monitoreo de la microcirculación}

Considerando el estado de la tecnología actual disponible debemos aceptar que existan dudas en la posibilidad de lograr este monitoreo a los pies de la cama del paciente ya que, por ejemplo, la afectación microcirculatoria no es similar en los diferentes sectores del organismo. Por esta razón es importante realizar una adecuada interpretación de estos y conocer especialmente sus limitaciones.

En la práctica habitual contamos con distintos métodos de evaluación de la microcirculación:

- Parámetros metabólicos: estos son medidas indirectas de oxigenación tisular: la saturación de oxígeno en sangre venosa mezclada $\left(\mathrm{S}_{\mathrm{V}} \mathrm{O}_{2}\right)$, de la vena cava superior $\left(\mathrm{ScvO}_{2}\right)$, lactato sanguíneo y las medidas derivadas del $\mathrm{CO}_{2}$ como la diferencia veno-arterial de $\mathrm{CO}_{2}\left(\mathrm{P}_{\mathrm{v}-\mathrm{a}} \mathrm{CO}_{2}\right.$ y $\left.\mathrm{P}_{\mathrm{vc}-\mathrm{a}} \mathrm{CO}_{2}\right)$ y la relación entre el gradiente veno-arterial de $\mathrm{CO}_{2}$ y la diferencia de contenido de oxígeno entre la sangre arterial y venosa $\left(\mathrm{C}_{\mathrm{a}-\mathrm{v}} \mathrm{O}_{2}\right.$ y $\left.\mathrm{C}_{\mathrm{a}-\mathrm{vc}} \mathrm{O}_{2}\right)$.

- Métodos anatómicos: las técnicas de microvideoscopía, como las imágenes registradas por la espectroscopía ortogonal polarizada (OPS), el Sidestream Darkfield (SDF) e Incident dark-field (IDF) pueden evaluar directamente las redes microvasculares de un epitelio delgado, como la microcirculación sublingual.

- Análisis funcional: el registro de la saturación tisular de oxígeno $\left(\mathrm{StO}_{2}\right)$ mediante espectroscopia cercano al infrarrojo acompañado de una prueba de isquemia puede ayudar a evaluar indirectamente la respuesta dinámica de la microcirculación.

\section{Saturación venosa de oxígeno}

La $\mathrm{S}_{\mathrm{V}} \mathrm{O}_{2}$ nos permite la medición indirecta de la relación entre la $\mathrm{DO}_{2}$ tisular $\left(\mathrm{DO}_{2}\right)$ y el consumo metabólico de $\mathrm{O}_{2}\left(\mathrm{VO}_{2}\right)$. De acuerdo con el principio de Fick, la $\mathrm{S}_{\mathrm{v}} \mathrm{O}_{2}$ se puede describir por medio de la siguiente ecuación: [ $\left.\mathrm{SaO}_{2}-\mathrm{VO}_{2} / \mathrm{GC}\right] \times[1 / \mathrm{Hb} \times$ $1,34]$. Se infiere que la $\mathrm{S}_{v} \mathrm{O}_{2}$ será el resultado de la interacción dinámica de diferentes variables que determinan el transporte y utilización de $\mathrm{O}_{2}$. De esta forma se ha planteado el siguiente modelo fisiopatológico (Figura 2): en la medida que la $\mathrm{DO}_{2}$ disminuye, el $\mathrm{VO}_{2}$ se mantiene por un aumento de la extracción

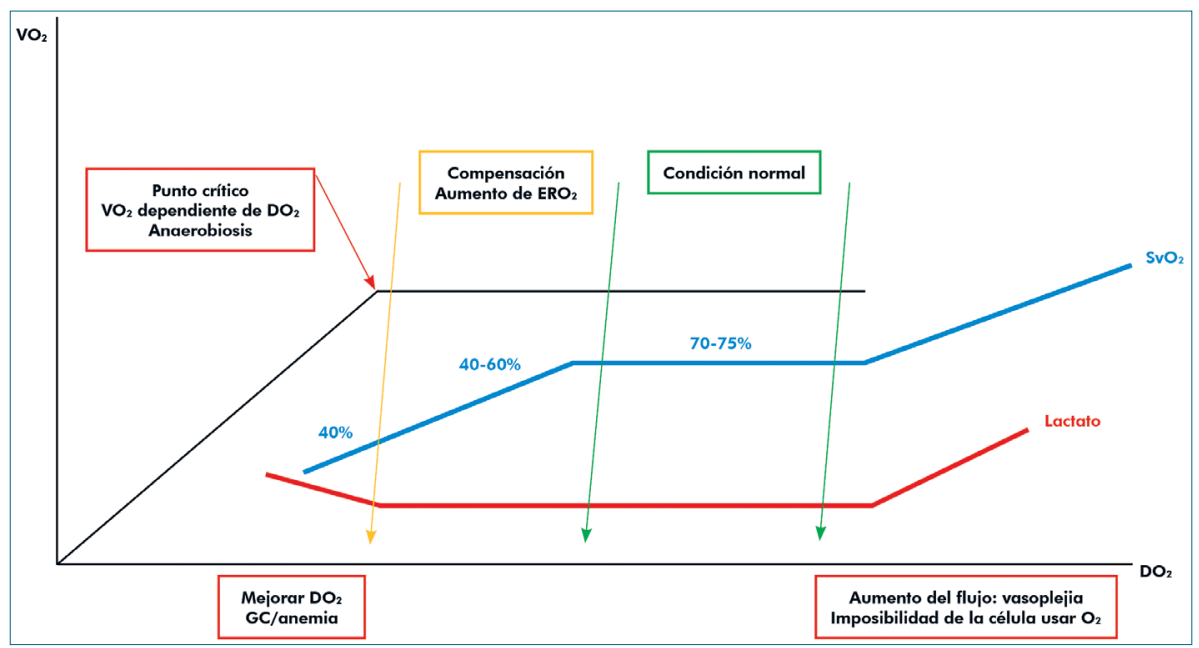

Figura 2. Muestra la relación entre la disponibilidad de $\mathrm{O}_{2}$ tisular $\left(\mathrm{DO}_{2}\right)$ y el consumo metabólico de $\mathrm{O}_{2}\left(\mathrm{VO}_{2}\right)$. A medida que la $\mathrm{DO}_{2}$ cae, el $\mathrm{VO}_{2}$ se mantiene por un aumento de la extracción de $\mathrm{O}_{2}\left(\mathrm{EO}_{2}\right)$ hasta un nivel crítico donde el $\mathrm{VO}_{2}$ se vuelve dependiente de la $\mathrm{DO}_{2}$. La $\mathrm{SVO}_{2}$ disminuirá primero por el aumento de $\mathrm{EO}_{2}$, al llegar al punto crítico aumenta el lactato en sangre por aumento del metabolismo anaerobio. 
de $\mathrm{O}_{2}\left(\mathrm{EO}_{2}\right)$. Este mecanismo compensatorio se mantiene hasta un nivel crítico donde no existe la capacidad de aumentar la extracción y el $\mathrm{VO}_{2}$ se vuelve dependiente de la $\mathrm{DO}_{2}$. La $\mathrm{S}_{\mathrm{V}} \mathrm{O}_{2}$ disminuirá en la medida que la $\mathrm{DO}_{2}$ disminuye reflejando primero el aumento de $\mathrm{EO}_{2}$, por tanto, valores de $\mathrm{S}_{\mathrm{v}} \mathrm{O}_{2}$ inferiores a $70 \%$ son un indicador temprano de lo que está sucediendo a nivel microcirculatorio. La magnitud de estos cambios también tiene importancia, se ha visto que valores por debajo de $40 \%$ reflejan que se superó la compensación del aumento de la $\mathrm{EO}_{2}$ y se correspondería a un estado de anaerobiosis. En lo que a CC respecta y especialmente si esta fue con CEC, es esperable la presencia de alteraciones en la relación $\mathrm{DO}_{2} \mathrm{NO}_{2}$, ya sea por: a) disminución de la $\mathrm{DO}_{2}$ como consecuencia de la anemia (por sangrado o dilucional) o disfunción miocárdica (disminución del $\mathrm{GC})$; b) alteraciones del $\mathrm{VO}_{2}$ con su disminución secundario al plano anestésico profundo, hipotermia o aumento de este asociado a la respuesta neuroendocrina por el estímulo quirúrgico, durante el pasaje de la anestesia a la sedación, uso de vasoactivos, recuperación de la temperatura o en la desvinculación de la ventilación mecánica.

Un aspecto al que se le presta menor atención es al análisis de valores por encima de lo normal, mayores a 75\%. Estos no garantizan una adecuada oxigenación tisular ya que pueden reflejar una imposibilidad de la célula de captar el $\mathrm{O}_{2}$ a pesar de una adecuada $\mathrm{DO}_{2}$. Esto ocurre en estados de alto gasto cardíaco como la vasoplejia severa durante la salida de CEC y suele asociar valores elevados de $\mathrm{S}_{\mathrm{V}} \mathrm{O}_{2}$ con otros indicadores de hipoxia tisular como la hiperlactatemia. Por lo tanto, son esperables las variaciones en los valores de $\mathrm{SvO}_{2}$ en un mismo paciente durante las diferentes fases perioperatorias no teniendo siempre connotación patológica.

Como conclusión: en primer lugar existe suficiente evidencia fisiopatológica y clínica para interpretar que una disminución de la $\mathrm{SvO}_{2}$ es un indicador precoz de la activación de mecanismos compensatorios a nivel microcirculatorio e incluso de agotamiento de estos en situaciones extremas. En segundo lugar, valores superiores a los normales, si bien aislados no significan necesariamente una alteración, deben ser un llamado de atención en la práctica clínica.

La principal limitación de esta medida está vinculada a la necesidad de utilizar un catéter en la arteria pulmonar. Se le ha atribuido desde una mayor mortalidad vinculado a su uso, hasta dificultades en su colocación e interpretación. No obstante y especialmente en cirugía cardíaca este sigue ocupando un lugar preponderante[19], dado que las medidas de la variables hemodinámicas (GC y resistencias sistémicas y pulmonares) han demostrado ser más fiables que las denominadas "no invasivas" y la medida de la $\mathrm{SvO}_{2}$ y las derivadas del $\mathrm{CO}_{2}$ han demostardo ser más confiables que aquellas obtenidas en la vena cava superior[20].

\section{¿Es posible sustituir la $\mathrm{SvO}_{2}$ por la $\mathrm{SvcO}_{2}$ en cirugía cardíaca?}

Estrictamente no existe una equivalencia entre ambas medidas, es decir, una no puede sustituir a la otra[21]. Las razones son en primer lugar, la $\mathrm{SvO}_{2}$ es el resultado de una mezcla de sangre proveniente de la vena cava superior (que drena fundamentalmente del sistema nervioso central), de la vena cava inferior (con $\mathrm{SO}_{2}$ variable según las circunstancias) y del cora- zón (seno coronario, venas accesorias y venas de Tebesio), que si bien aporta poco volumen, la sangre presenta una baja $\mathrm{SO}_{2}$ (aproximadamente 30\%) dada por la alta extracción de oxígeno del músculo cardíaco[22],[23]. En segundo lugar, estos tres territorios tendrán respuestas adaptativas diferentes frente a la anestesia y especialmente frente a los cambios hemodinámicos que ocurren en cirugía cardíaca. Es bien conocido que la anestesia general determina una disminución significativa del consumo cerebral (afectando principalmente la $\mathrm{SvCO}_{2}$ ), mientras que frente a una disminución de la $\mathrm{DO}_{2}$ (por anemia o caída del GC) existirá una redistribución del flujo desde el sector esplácnico hacia el cerebral y cardíaco. De esta forma en un mismo paciente dependiendo del momento de la cirugía, así como de la situación hemodinámica, el comportamiento de la $\mathrm{SvCO}_{2}$ no acompañará el de la $\mathrm{SvO}_{2}$ por lo que no sería aconsejable basar nuestras medidas terapéuticas exclusivamente en este valor. Conociendo estas limitaciones en su interpretación, la $\mathrm{SvCO}_{2}$ ha mostrado ser útil en la práctica clínica tanto cuando se presentan valores extremadamente bajos como cuando estos son elevados[24]. Por lo tanto, con la salvedad de determinados contextos clínicos, en aquellos pacientes que no tienen indicación de cateterización arterial pulmonar, el uso de la $\mathrm{ScvO}_{2}$ es un recurso válido como sustituto de $\mathrm{S}_{\mathrm{v}} \mathrm{O}_{2}$, asociado a otros parámetros.

\section{Lactato}

El lactato es uno de los intermediarios más importantes en el metabolismo de carbohidratos y aminoácidos no esenciales. Sus valores en sangre $(0,5-1,8 \mathrm{mmol} / \mathrm{L})$ reflejan el balance entre su producción y metabolización tisular. Debe diferenciarse dos formas de generación de lactato ya que se corresponden con dos situaciones diferentes, que a su vez requieran medidas diferentes, especialmente en CC con CEC. Ellos son: 1) tipo A (anaeróbica). En condiciones de anaerobiosis la glucolisis genera dos moléculas de piruvato produciendo 2 moles de ATP por mol de glucosa. El piruvato es luego convertido en lactato. Durante la hipoperfusión manifiesta u oculta, el aumento de lactato generado anaeróbicamente se libera en la circulación alertando precozmente de esta situación. Como fue analizado previamente (Figura 2) la producción de lactato anaeróbico aumenta cuando la $\mathrm{DO}_{2}$ cae por debajo de un punto crítico en el que el $\mathrm{VO}_{2}$ se vuelve dependiente del suministro y será revertido si se actúa sobre este fallo. Por otra parte, es un indicador de evolución ya que cuando se restaura la $\mathrm{DO}_{2}$, el lactato puede ser eliminado por las mismas células donde fue liberado, reconvertido en piruvato se incorpora en el ciclo de Krebs y normalizando sus valores lo cual traduce una reanimación exitosa; 2) tipo B (aeróbica). Durante la inflamación sistémica, la sepsis y el shock, la activación del complejo neurohormonal determina a un aumento de los niveles de adrenalina, promoviendo así la glucogenólisis, la glucólisis aeróbica y la generación de piruvato. Dependiendo de la situación clínica la capacidad de metabolizarlo puede verse sobrepasada por lo que aumenta la conversión a lactato y este es, entonces, utilizado por diferentes órganos. La producción de lactato impulsada por adrenérgicos es un proceso aeróbico, ya que ocurre en presencia de una oxigenación muscular adecuada y como consecuencia a la respuesta al estrés y evidencia una reserva metabólica proporcionando un recurso energético ante un aumento de las demandas[25]. 
En la práctica habitual se define hiperlactatemia ( $\mathrm{HL})$ cuando los niveles de lactato son mayores a $2 \mathrm{mmol} / \mathrm{l}$, siendo severa por arriba de $5 \mathrm{mmol} / \mathrm{l}$ En pacientes críticos, la $\mathrm{HL}$ tipo A es un marcador de persistencia de la falla circulatoria, y la severidad de su aumento está directamente relacionado con la gravedad del estado de shock y las tasas de mortalidad[26].

En los pacientes sometidos a CC, especialmente con CEC, existen situaciones específicas que deben tomarse en cuenta al momento de analizar estos valores. En primer lugar, la $\mathrm{HL}$ es frecuente, variando desde el 5\% durante la CEC[26] hasta del $20 \%$ a $32 \%$ cuando se incluye el período del posoperatorio[27],[28]. Otro aspecto importante a considerar es el punto de corte para la definición de $\mathrm{HL}$, mientras que en pacientes críticos se considera $2 \mathrm{mmol} / \mathrm{l}$, en CC este oscila entre 3 y 5 $\mathrm{mmol} / \mathrm{l}$ dada las características especiales del metabolismo del lactato en estas condiciones. En la adecuada interpretación deben tomarse en cuenta los factores determinantes de la HL tipo A como de la tipo B (respuesta neurohumoral e inflamatoria con aumento de adrenalina), a lo que debemos sumar posibles alteraciones en su metabolización, dada la reducción del flujo esplácnico (hígado). En el contexto de la CC con CEC se ha sugerido que la $\mathrm{HL}$ tipo A predomina durante la CEC en las primeras horas del posoperatorio ("hiperlactatemia de inicio temprano") siendo la que se asocia a peor evolución, mientras que existe otro ascenso del lactato tardío, 6 a 12 h luego del ingreso a la unidad de posoperatorio (hiperlactatemia de inicio tardío) de buena evolución y resolución espontánea que se asocia a HL tipo $B[29]$.

En lo que la mayoría de los estudios coinciden es: a) La HL se asoció a los tiempos de CEC, mostrando un punto de corte de 96 minutos como predictivo[26]. Otros autores agregan el tiempo del procedimiento anestésico-quirúrgico, del clampeo aórtico y la hipotensión al inicio de la CEC[27]-[30]; b) existe una fuerte asociación entre la $\mathrm{HL}$ y la disminución de la $\mathrm{DO}_{2}$ medida durante la CEC, los valores de lactato se incrementaron con valores de $\mathrm{DO}_{2}$ por debajo de $260 \mathrm{ml} / \mathrm{minuto} / \mathrm{m}^{2}$; c) casi invariablemente la $\mathrm{HL}$ se asoció a hiperglicemia. Esto refleja que la HL será producto de un complejo proceso que involucra tanto los mecanismos de producción como también los de eliminación. La asociación con hiperglicemia hace pensar en un exceso de producción de lactato provocada por la respuesta neuroendocrina a la cirugía, especialmente adrenérgica ( $\mathrm{HL}$ tipo $\mathrm{B}) ; \mathrm{d}$ ) Por último la $\mathrm{HL}$ se asoció significativamente a mayor morbilidad, especialmente al tiempo de ventilación mecánica y estadía en unidades de cuidados críticos[27]-[30] Demers y cols[31] encontraron una mayor mortalidad posoperatoria en pacientes que presentaron niveles máximos de lactato en sangre de 4,0 $\mathrm{mmol} / \mathrm{l}$ o más durante la $C E C$, con un riesgo relativo $[\mathrm{RR}]=9,0$. La inestabilidad hemodinámica posoperatoria presentó un RR = 3,4 y se produjeron complicaciones posoperatorias importantes en el $43,2 \%$ de los que presentaron $\mathrm{HL}$ frente al $21,8 \%$ de los que no la presentaron ( $p<0,001, R R=2,7)$. El análisis de regresión logística reveló que los niveles máximos de lactato en sangre de $4 \mathrm{mmol} / \mathrm{L}$ o más durante la CEC estaban fuertemente asociados con la mortalidad $(p=0,0001)$ y la morbilidad $(p=$ $0,013)$ posoperatoria.

La combinación de diferentes variables mejorará el desempeño de cada una de ellas. Un estudio[32] demostró que $\mathrm{SvCO}_{2}$ y el lactato utilizados individualmente no fueron capaces de detectar hipoperfusión oculta en el posoperatorio de pacien- tes que padecieron una CC con CEC. Sin embargo, aquellos pacientes que asociaron $\mathrm{SvCO}_{2}<$ a $70 \mathrm{mmHg}$ con lactato de 4 $\mathrm{mmol} / \mathrm{L}$ desarrollaron mayores complicaciones posoperatorias.

Por último, se ha propuesto que la disminución de lactato $>50 \%$ en $6 \mathrm{~h}$, se ha relacionado con una mejor evolución en pacientes críticos (clearence de lactato). No obstante, persisten dudas en cuanto a su utilización como parámetro de resucitación dada la complejidad tanto en su producción como en su eliminación.

En suma, la monitorización del lactato es un buen indicador de hipoperfusión oculta en CC con CEC. Conociendo las limitaciones debemos tener en cuenta no considerar un valor aislado, sino una secuencia de ellos y su asociacion con otros parámetros.

\section{Medidas derivadas del metabolismo de $\mathrm{CO}_{2}$ de la $\mathrm{PCO}_{2}$}

Se ha propuesto que la diferencia veno-arterial de $\mathrm{CO}_{2}$, permitiría detectar alteraciones del flujo sistémico y regional, mientras que la relación de estos con el contenido de oxígeno entre la sangre arterial y la venosa podrían estimar la dependencia entre la $\mathrm{DO}_{2}$ y el $\mathrm{VO}_{2}[33],[34]$. Esta interpretación se basa en el principio de Fick, donde la producción total de $\mathrm{CO}_{2}\left(\mathrm{VCO}_{2}\right)$ será igual al producto del GC por la diferencia del contenido veno- arterial de $\mathrm{CO}_{2}$. Asumiendo que, en condiciones estables, existe una relación casi lineal entre las presiones parciales $\left(\mathrm{PCO}_{2}\right)$ y el contenido de $\mathrm{CO}_{2}\left(\mathrm{CCO}_{2}\right)$, se sustituye este por la $\mathrm{PCO}_{2}$. Por lo tanto, el GC $=\mathrm{VCO}_{2} / \mathrm{P}_{\mathrm{v}-\mathrm{a}} \mathrm{CO}_{2}$ es decir que, existirá una relación lineal inversa entre $\mathrm{GC}$ y $\mathrm{P}_{\mathrm{v}-\mathrm{a}} \mathrm{CO}_{2}$. Por los objetivos de este artículo nos concentramos en el cociente respiratorio $(C R)$, el cual se define como la relación entre $\mathrm{VCO}_{2} \mathrm{NO}_{2}$. Mientras que la $\mathrm{VCO}_{2}$ será igual a $\mathrm{GC} \times \mathrm{P}_{\mathrm{v}-\mathrm{a}} \mathrm{CO}_{2}$ el $\mathrm{VO}_{2}$ será igual al $\mathrm{GC} \times \mathrm{C}_{\mathrm{a}-\mathrm{v}} \mathrm{O}_{2}$. Al suprimir el GC, y asumiendo que la $\mathrm{P}_{\mathrm{v}} \mathrm{CO}_{2} \mathrm{y}$ contenido venoso de $\mathrm{O}_{2}$ de la sangre venosa mezclada es igual al contenido venoso de $\mathrm{O}_{2}$ obtenido de la vena cava superior el CR será igual $\mathrm{P}_{\mathrm{vc}-\mathrm{a}} \mathrm{CO}_{2} / \mathrm{C}_{\mathrm{a}-\mathrm{v} \mathrm{c}} \mathrm{O}_{2}$. Se ha sugerido que valores superiores a $1,4 \mathrm{~mm} \mathrm{Hg} / \mathrm{ml}$ indicarían metabolismo anaeróbico Frente a una disminución de la $\mathrm{DO}_{2}$ caerán tanto el $\mathrm{VO}_{2}$ como la producción de $\mathrm{CO}_{2}$ por lo que, el CR se mantendría dentro de valores normales. Cuando la caída de la $\mathrm{DO}_{2}$ es "crítica", el $\mathrm{VO}_{2}$ será dependiente de la $\mathrm{DO}_{2}$ y por lo tanto disminuirá al igual que la $\mathrm{VCO}_{2}$ "aeróbica", por lo que el cociente se mantendrá. Sin embargo, progresivamente existirá un aumento de la $\mathrm{VCO}_{2}$ desde las vías "anaeróbicas" aumentando entonces la $\mathrm{P}_{v} \mathrm{CO}_{2}$, la $\mathrm{P}_{\mathrm{v}-\mathrm{a}} \mathrm{CO} 2$ y por consiguiente el cociente $\mathrm{P}_{\mathrm{v}-\mathrm{a}} \mathrm{CO}_{2} /\left(\mathrm{C}_{\mathrm{a}-\mathrm{v}} \mathrm{O}_{2}\right)^{\mathrm{v}}$. Un valor superior a 1,4 sería entonces indicador de hipoxia tisular. Su utilidad en CC muestra resultados contradictorios, Wei Du y cols.[35] encontraron que un $\mathrm{P}_{\mathrm{v}-\mathrm{a}} \mathrm{CO}_{2} / \mathrm{C}_{\mathrm{a}-\mathrm{v}} \mathrm{O}_{2} \geq$ a 1,6 mm Hg/ $\mathrm{ml}$ fue capaz de predecir la condición de respondedor con una sensibilidad del 68,8\%, una especificidad de $87,5 \%$ y un área bajo la curva de 0,77 $\pm 0,10(p=0,032)$. Sin embargo, otros autores[36] no encuentran correlación estadísticamente significativa con el lactato $(r=0,052 p=0,587)$, ni que sea predictor de las modificaciones del $\mathrm{VO}_{2}$ frente al desafío de volumen, con un área bajo la curva de 0,53 $(0,4-0,65)$ y $p=0,71$.

Tampoco ha sido concluyente la asociación de este cociente con las complicaciones posoperatorias.

La CC, especialmente con CEC presenta características que deben tomarse en cuenta al momento de utilizar el $\mathrm{P}_{\mathrm{v}-\mathrm{a}} \mathrm{CO}_{2} / \mathrm{C}_{\mathrm{a}}$. ${ }_{\checkmark} \mathrm{O}_{2}[37]$. En primer lugar, el principio de Fick tiene como reque- 
rimiento una situación estable para asumir la linealidad entre la $\mathrm{PCO}_{2}$ y el $\mathrm{CCO}_{2}$ lo que no ocurre en $\mathrm{CC}$ con CEC. Las razones son: 1) la anemia dilucional afecta la linealidad en la curva de disociación del $\mathrm{CO}_{2}$. Esta se aplana, tanto en la sangre arterial como en la venosa recuperándose parcialmente sólo en la sangre arterial, mientras que persiste en la venosa más allá de la CEC. Una vez corregida la hemoglobina, esto no se acompaña de una corrección de la curva de disociación; 2) hipotermia, los cambios de temperatura afectan el $\mathrm{VO}_{2}$, la solubilidad y la producción de $\mathrm{CO}_{2}$ varias horas después de finalizada la cirugía; 3) las alteraciones de flujos regionales y por tanto del lavado de $\mathrm{CO}_{2}$ en la periferia son frecuentes después de la cirugía cardíaca y es reflejo de alteraciones de la perfusión sistémica y regional más que de la hipoxia tisular; 4) drogas vasoactivas que afectan directamente el $\mathrm{VO}_{2}$ y la $\mathrm{VCO}_{2}$ y 5) los diferentes niveles de anestesia/sedación pueden explicar el aumento de la extracción de oxígeno.

En segundo lugar, se asume que los valores obtenidos para determinar $\mathrm{P}_{\mathrm{v}-\mathrm{a}} \mathrm{CO}_{2} / \mathrm{C}_{\mathrm{a}-\mathrm{v}} \mathrm{O}_{2}$ son intercambiables con los obtenidos desde la arteria pulmonar, que como vimos previamente no son equivalentes, especialmente en CC con CEC por lo que deben considerarse con precaución.

No obstante, en pacientes críticos el cociente $\mathrm{P}_{\mathrm{vc}-\mathrm{a}} \mathrm{CO}_{2} / \mathrm{C}_{\mathrm{a}-}$ ${ }_{v c} \mathrm{O}_{2}$ ha mostrado ser útil como una herramienta pronóstica, probablemente debido a que las condiciones de medidas no son comparables. Mientras que en estos la temperatura, hematocrítco, uso de drogas, etc se mantienen estables en los procedimientos de CC, como vimos, en estos cambian bruscamente en diferentes direcciones y por períodos de tiempo variables.

Como conclusión en cirugía cardíaca la relación $\mathrm{P}_{\mathrm{v}-\mathrm{a}} \mathrm{CO}_{2} / \mathrm{C}_{\mathrm{a}-\mathrm{a}}$ $\mathrm{O}_{2}$ está afectada por cambios fisiopatológicos que afectarán la relación entre la $\mathrm{PCO}_{2}$ y la $\mathrm{CCO}_{2}$ haciendo que estas mediciones sean menos sensibles a los cambios en la relación $\mathrm{DO}_{2} \mathrm{NO}_{2}$. Las variables derivadas del $\mathrm{CO}_{2}$ deben usarse con cautela para guiar el soporte hemodinámico y monitorear la oxigenación tisular durante la cirugía cardíaca.

\section{Videomicroscopía}

La videomicroscopía es un método no invasivo donde es posible observar la microcirculación in vivo y puede ser utilizado para la monitorización microcirculatoria. Esta se puede observar colocando el dispositivo sobre las membranas mucosas que ilumina el área de interés con luz polarizada, mientras que la imagen de la luz emitida pasa a través de un segundo polarizador (analizador), orientado en un plano ortogonal al plano de la iluminación. Al seleccionar una longitud de onda comprendida dentro del espectro de absorción de la hemoglobina, los eritrocitos se verán oscuros y los leucocitos como cuerpos refringentes. Por lo tanto, la pared de los vasos no se visualiza directamente y las imágenes de la microcirculación dependen de la presencia de eritrocitos (Figura 3). La calidad de los dispositivos ha evolucionado técnicamente proporcionando imágenes de mejor resolución. La ubicación más estudiada para aplicar estas técnicas ha sido la región sublingual por su fácil acceso, se puede utilizar en pacientes despiertos como dormidos y su vascularización está cerca del cerebro y el corazón.

Los modelos de alteraciones de la microcirculación que definimos previamente están basados en estos hallazgos[5].

Las variables que pueden ser analizadas a través de estas

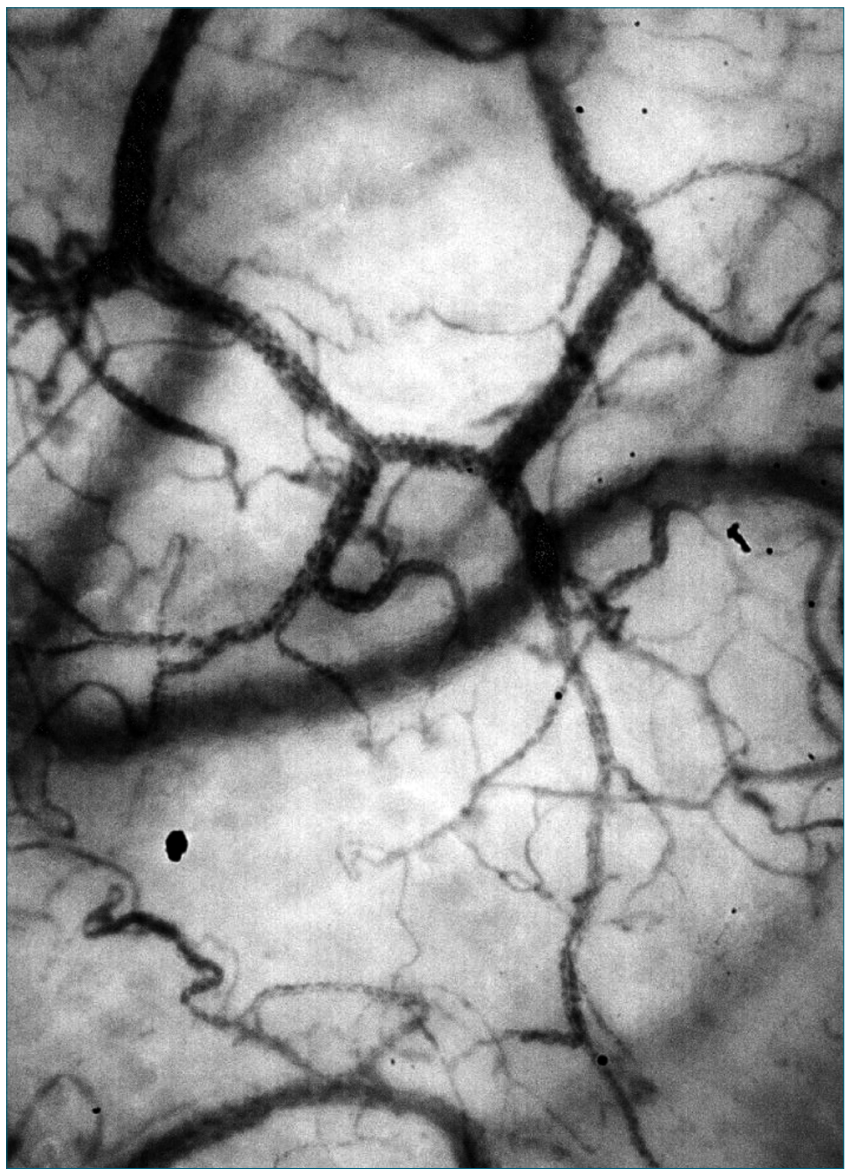

Figura 3. Muestra imágenes de la microcirculación a nivel sublingual tomadas con un microscopio Cytocam IDF durante una cirugía cardíaca. En ella se distinguen los glóbulos rojos en los capilares de diferentes tamaños, así como las vénulas poscapilares de un mayor diámetro en el fondo de la imagen.

imágenes son las siguientes: 1) densidad de los vasos (DV): número de vasos que pasan por un sector dado; 2) índice de flujo microvascular (IFM) corresponde al flujo predominante en los vasos del campo antes mencionado y se clasifican: sin flujo (0), flujo intermitente (1), flujo lento (2), normal (3). se ha planteado la posibilidad de un flujo (4) rápido[38] el cual ha sido cuestionado; 3) Densidad capilar funcional (DCF) que se refiere a la cantidad de vasos efectivamente perfundidos; 4) heterogeneidad de flujo: IFM mayor (en el sitio que es mayor) menos el menor IFM, dividido el promedio de IFM en el mismo campo.

En CC la cantidad de vasos no se afecta mayormente, pero sí la proporción de vasos efectivamente perfundidos[39], especialmente cuando esta se realizó con CEC, donde las alteraciones pueden persistir hasta $24 \mathrm{~h}$ luego de finalizada la cirugía. El efecto del procedimiento anestésico en sí mismo mostró ser sutil y transitorio.

Debido a limitaciones metodológicas no ha sido posible establecer si existe o no asociación entre un patrón de alteración microcirculatoria y la evolución de los pacientes sometido a CC.

Esta tecnología presenta considerables limitaciones: 1) requiere un entrenamiento específico para la obtención de imágenes; 2) el análisis de las imágenes no se realiza en tiempo 
real. Si bien existen métodos que podrían hacerlo estos no han sido validados[40]; 3) el lugar de mayor accesibilidad es el lecho sublingual por lo que las mediciones no siempre son extrapolables a otros territorios[41].

En suma, a diferencia de las variables analizadas anteriormente, las aportadas por la videomicroscopia nos permiten analizar directamente el estado de la microcirculación. No obstante su mayor utilidad hasta el momento ha sido una mejor comprensión de la fisiopatología de esta durante la CC. Su principal limitación es la imposibilidad de analizar los resultados en tiempo real y de esa forma poder evaluar la evolución de estos pacientes y su respuesta al tratamiento.

\section{Espectroscopía cercana al infrarrojo}

EI NIRS (de su sigla en inglés near-infrared spectroscopic) ofrece un método no invasivo, continuo para monitorizar la oxigenación tisular. Puede discriminar diferentes compuestos de acuerdo con la longitud de onda que reflejan, absorben o dispersan, la intensidad con que la emiten y el color. Es así que permite detectar y cuantificar la desoxi y oxihemoglobina en un tejido, reflejando el grado de hipoxia del tejido observado en tiempo real, antes que se produzcan cambios en los niveles séricos de lactato y exceso de bases[42]. La monitorización de la saturación cerebral basada en NIRS cuenta con múltiples aplicaciones en cirugía cardíaca y se ha extendido a otros lechos tales como el riñón y el lecho esplácnico durante cirugía cardíaca infantil y más recientemente a nivel muscular[43].

La medición de la saturación de oxígeno tisular periférico $\left(\mathrm{StO}_{2}\right)$ mediante NIRS en combinación con un test de oclusión vascular (VOT) ha sido descrito como un método práctico para evaluar la perfusión tisular y la vasorreactividad microcirculatoria (Figura 4). Durante el período breve de isquemia se pro-

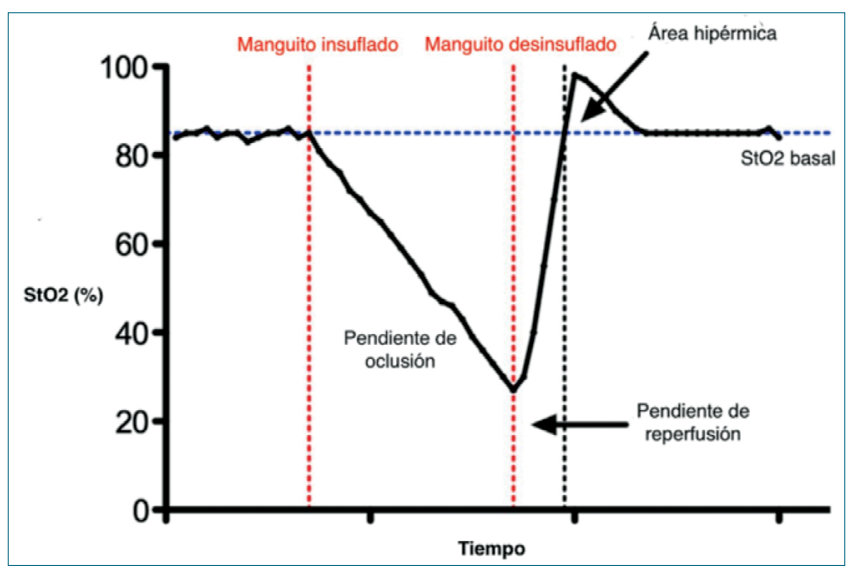

Figura 4. Cambios en la saturación de oxígeno tisular durante el test de oclusión vascular. Se muestra la secuencia de la $\mathrm{StO}_{2}$ en el tiempo luego de la oclusión vascular. Luego del registro basal $\left(\mathrm{StO}_{2}\right.$ basal) se realiza la oclusión del manguito. Inmediatamente luego se aprecia la pendiente decreciente de la $\mathrm{StO}_{2}$ durante la oclusión lo que representa la demanda metabólica. Luego de liberar la oclusión se verifica una pendiente ascendente que evalúa la capacidad de respuesta microcirculatoria. La pendiente de reperfusión se calculará desde la liberación del torniquete hasta que se alcance el $85 \%$ de la $\mathrm{StO}_{2}$ de línea de base. También puede verse un área hiperémica que corresponde al aumento de $\mathrm{StO}_{2}$ sobre el valor basal $(\Delta \mathrm{StO} 2)$. mueve la liberación de ON endógeno a partir del endotelio que resulta en hiperemia sujeta a la disponibilidad de dicho vasodilatador. Puede considerarse como una prueba de reactividad microvascular para evaluar la capacidad del tejido para adaptar su extracción de oxígeno al transporte de este después de un estímulo hipóxico. En los pacientes con disfunción a dicho nivel la fase hiperémica está impedida evidenciándose en la pendiente de reperfusión[44].

El sensor de medición se recomienda colocarlo en la eminencia tenar dado que es un área con una respuesta vascular amplificada respecto a otros tejidos, hay poca influencia de señal de la piel y el tejido graso[42],[45].

La inducción anestésica genera cambios a nivel macrocirculatorio como resultado de: disminución del tono vascular, del retorno venoso y de la contractilidad cardiaca. Sin embargo, no son tan evidentes los cambios generados a nivel microcirculatorios, encontrándose en la literatura resultados contradicto$\operatorname{rios}[46],[47]$.

En pacientes sometidos a cirugía cardíaca se han descrito diferencias estadísticamente significativas en $\mathrm{StO}_{2}$ y la pendiente de reperfusión comparados con voluntarios sanos. La respuesta hiperémica, reflejo del aumento del flujo sanguíneo oxigenado y del reclutamiento capilar, fue menor en pacientes con peor evolución posoperatoria[46].

Se pueden detallar como limitaciones de esta técnica:

- Artefactos como la luz externa u otras sustancias diferentes a la $\mathrm{Hb}$ que pueden alterar sus valores.

- Existe una variabilidad interindividual de 10\%-15\% lo que provoca variaciones en los valores de referencia, por lo que es necesario pautar un valor de referencia basal de cada paciente, más que un valor absoluto.

- Evalúa un territorio vascular específico lo que no siempre es extrapolable a otros territorios.

- No todos los territorios tisulares plausibles de valoración son alcanzados por la profundidad de la luz emitida, siendo una limitante aquellos territorios que se encuentran a más de $2,5 \mathrm{~cm}$ de profundidad de la piel.

Pese a las anteriores limitaciones mencionadas, el NIRS es una herramienta clínica útil y con eficacia demostrada, siendo aún insuficiente la evidencia que respalde las interpretaciones de la VOT especialmente en CC.

\section{Conclusiones}

En la Tabla 1 se resumen los métodos utilizados habitualmente para monitorizar la microcirculación en CC.

La controversia en dirigir nuestros esfuerzos terapéuticos hacia la macro y/o la microcirculación no ha avanzado en los últimos 20 años. La pérdida de la coherencia hemodinámica podría explicar la mala evolución de algunos pacientes pese a haber logrado valores macrohemodinámicos adecuados. La presencia de alteraciones microcirculatorias incluso puede agravarse si se mantienen medidas que no tomen en cuenta esta coherencia.

El principal desafío al que nos enfrentamos consiste en desarrollar tratamientos específicos para cada uno de los territorios que no afecten en forma negativa al que no est\{a dirigido.

El objetivo final debe ser mantener la perfusión tisular, la 


\begin{tabular}{|c|c|c|c|}
\hline Variable & Monitor & Ventaja & Desventaja \\
\hline $\mathrm{S}_{\mathrm{v}} \mathrm{O}_{2}$ & Catéter en arteria pulmonar & $\begin{array}{l}\text { Parámetro metabólico que refleja la } \\
\text { extracción de oxígeno tisular }\end{array}$ & $\begin{array}{l}\text { Para su registro requiere la } \\
\text { colocación de un catéter en la } \\
\text { arteria pulmonar, maniobra invasiva } \\
\text { no libre de complicaciones }\end{array}$ \\
\hline $\mathrm{S}_{\mathrm{vc}} \mathrm{O}_{2}$ & Catéter en la vena cava superior & $\begin{array}{l}\text { Menos invasivo que el registro de } \\
\text { la } \mathrm{S}_{\mathrm{v}} \mathrm{O}_{2}\end{array}$ & $\begin{array}{l}\text { Sus valores están influenciados } \\
\text { por muchos factores por lo que su } \\
\text { interpretación debe ser cautelosa }\end{array}$ \\
\hline $\mathrm{P}_{\mathrm{v}-\mathrm{a}} \mathrm{CO}_{2}$ y $\mathrm{P}_{\mathrm{v}-\mathrm{a}} \mathrm{CO}_{2} / \mathrm{C}_{\mathrm{av}} \mathrm{O}_{2}$ & $\begin{array}{l}\text { Catéter en arteria pulmonar y } \\
\text { catéter arterial }\end{array}$ & $\begin{array}{l}\text { Aumentos en esta diferencia } \\
\text { pueden reflejar cambios en el flujo } \\
\text { sanguíneo sistémico }\end{array}$ & $\begin{array}{l}\text { Requiere la colocación de un catéter } \\
\text { en arteria pulmonar. En CC esta } \\
\text { variable se ve afectada por muchos } \\
\text { factores independiente del flujo } \\
\text { sanguíneo }\end{array}$ \\
\hline $\mathrm{P}_{\mathrm{vc}-\mathrm{a}} \mathrm{CO}_{2}$ y $\mathrm{P}_{\mathrm{vc}-\mathrm{a}} \mathrm{CO}_{2} / \mathrm{C}_{\mathrm{avc}} \mathrm{O}_{2}$ & $\begin{array}{l}\text { Catéter en vena cava superior y } \\
\text { catéter arterial }\end{array}$ & $\begin{array}{l}\text { Menos invasivo que } \mathrm{P}_{\mathrm{va}} \mathrm{CO}_{2} \text { por lo } \\
\text { que se puede utilizar en cualquier } \\
\text { paciente que tenga una vía venosa } \\
\text { central y una vía arterial }\end{array}$ & $\begin{array}{l}\text { Se ve afectada por varios factores } \\
\text { comunes en la CC. Refleja } \\
\text { mayormente el flujo sanguíneo } \\
\text { regional }\end{array}$ \\
\hline $\begin{array}{l}\text { Densidad capilar índice de flujo } \\
\text { microvascular densidad capilar } \\
\text { funcional heterogeneidad de flujo }\end{array}$ & Videomicroscopia(OPS, SDF, IDF) & $\begin{array}{l}\text { Permiten el diagnóstico } \\
\text { anatomofuncional de la } \\
\text { microcirculación. Método no } \\
\text { invasivo }\end{array}$ & $\begin{array}{l}\text { Requiere entrenamiento para } \\
\text { realizarla e interpretar los datos, } \\
\text { los cuales se hacen en diferido }\end{array}$ \\
\hline $\begin{array}{l}\text { Pendiente de desaturación tisular. } \\
\text { Pendiente de recuperación. Área } \\
\text { hiperémica. Área de desaturación }\end{array}$ & $\begin{array}{l}\text { Espectroscopia de infrarrojo (NIRS) } \\
\text { acompañado de estímulo isquémico } \\
\text { (VOT) }\end{array}$ & $\begin{array}{l}\text { No invasivo. Refleja varios } \\
\text { componentes de la perfusión } \\
\text { tisular. Fácil realización }\end{array}$ & $\begin{array}{l}\text { Dependiente de la perfusión tisular } \\
\text { regional. Se ve afectado por varios } \\
\text { artefactos }\end{array}$ \\
\hline
\end{tabular}

$\mathrm{S}_{\mathrm{v}} \mathrm{O}_{2}$ : saturación de oxígeno en la arteria pulmonar; $\mathrm{S}_{\mathrm{vc}} \mathrm{O}_{2}$ : saturación de oxígeno en la vena cava superior; $\mathrm{P}_{\mathrm{v}-\mathrm{a}} \mathrm{CO}_{2}$ y $\mathrm{P}_{\mathrm{vc}-\mathrm{a}} \mathrm{CO}_{2}$ : diferencia veno arterial de dióxido de carbono en la arteria pulmonar y en la vena cava superior respectivamente; $C_{a-v} \mathrm{O}_{2}$ y $C_{a v c} \mathrm{O}_{2}$ : contenido arterio venoso de oxígeno registrado en la arteria pulmonar y en la vena cava superior respectivamente; OPS: Ortogonal Polarized Spectroscopy; SDF: Sidestream Darkfield; IDF: Incident dark-field; NIRS: Near infrared spectroscopy; VOT: vascular occlusion test; CC: cirugía cardíaca.

oxigenación celular y la eliminación de los desechos del metabolismo con un tratamiento dirigido a ambos territorios (macrohemodinamia y microcirculación).

Si bien no existe al momento ningún método que nos permita evaluar con certeza el estado de la microcirculación en todos los territorios, el conocimiento profundo de los que contamos, tanto sus indicaciones como limitaciones, nos permitirá una mejor interpretación de lo que sucede a ese nivel y por tanto establecer la mejor terapéutica.

\section{Referencias}

1. Mayer J, Boldt J, Mengistu AM, Röhm KD, Suttner S. Goaldirected intraoperative therapy based on autocalibrated arterial pressure waveform analysis reduces hospital stay in high-risk surgical patients: a randomized, controlled trial. Crit Care. 2010;14(1):R18. https://doi.org/10.1186/cc8875

2. Pölönen $P$, Ruokonen $E$, Hippeläinen $M$, Pöyhönen $M$, Takala J. A prospective, randomized study of goal-oriented hemodynamic therapy in cardiac surgical patients. Anesth Analg. 2000 May;90(5):1052-9. https://doi.org/10.1097/00000539200005000-00010

3. Giglio M, Dalfino L, Puntillo F, Rubino G, Marucci M, Brienza N. Haemodynamic goal-directed therapy in cardiac and vascular surgery. A systematic review and meta-analysis. Interact Cardiovasc Thorac Surg. 2012 Nov;15(5):878-87. https://doi.org/10.1093/ icvts/ivs323
4. Gurgel ST, do Nascimento P Jr. Maintaining tissue perfusion in high-risk surgical patients: a systematic review of randomized clinical trials. Anesth Analg. 2011 Jun;112(6):1384-91. https:// doi.org/10.1213/ANE.0b013e3182055384

5. Ince $\mathrm{C}$. Hemodynamic coherence and the rationale for monitoring the microcirculation. Crit Care. 2015;19 Suppl 3(Suppl 3):S8. Epub 2015 Dec 18. https://doi.org/10.1186/cc14726

6. Segal SS. Regulation of blood flow in the microcirculation. Microcirculation. 2005 Jan-Feb;12(1):33-45. https://doi. org/10.1080/10739680590895028

7. Koning NJ, Atasever B, Vonk AB, Boer C. Changes in microcirculatory perfusion and oxygenation during cardiac surgery with or without cardiopulmonary bypass. J Cardiothorac Vasc Anesth. 2014 Oct;28(5):1331-40. https://doi.org/10.1053/j. jvca.2013.04.009

8. Warren OJ, Smith AJ, Alexiou C, Rogers PL, Jawad N, Vincent C, Darzi AW, Athanasiou T. The inflammatory response to cardiopulmonary bypass: part 1-mechanisms of pathogenesis. J Cardiothorac Vasc Anesth. 2009 Apr;23(2):223-31. https://doi. org/10.1053/j.jvca.2008.08.007

9. Shoemaker WC, Appel PL, Kram HB, Waxman K, Lee TS. Prospective trial of supranormal values of survivors as therapeutic goals in high-risk surgical patients. Chest. 1988 Dec;94(6):1176-86. https://doi.org/10.1378/chest.94.6.1176

10. Gattinoni L, Brazzi L, Pelosi P, Latini R, Tognoni G, Pesenti A, Fumagalli R. A trial of goal-oriented hemodynamic therapy in critically ill patients. SvO2 Collaborative Group. N Engl J Med. 1995 Oct 19;333(16):1025-32. https://doi.org/10.1056/ 


\section{NEJM199510193331601}

11. De Backer D, Ortiz JA, Salgado D. Coupling microcirculation to systemic hemodynamics. Curr Opin Crit Care. 2010 Jun;16(3):250-4. https://doi.org/10.1097/ MCC.0b013e3283383621

12. De Backer D, Creteur J, Dubois MJ, Sakr Y, Koch M, Verdant C, Vincent JL. The effects of dobutamine on microcirculatory alterations in patients with septic shock are independent of its systemic effects. Crit Care Med. 2006 Feb;34(2):403-8. https://doi. org/10.1097/01.CCM.0000198107.61493.5A

13. Dubin A, Pozo MO, Casabella CA, Pálizas F Jr, Murias G, Moseinco MC, Kanoore Edul VS, Pálizas F, Estenssoro E, Ince C. Increasing arterial blood pressure with norepinephrine does not improve microcirculatory blood flow: a prospective study. Crit Care. 2009;13(3):R92. https://doi.org/10.1186/cc7922

14. Hamilton MA, Cecconi M, Rhodes A. A systematic review and meta-analysis on the use of preemptive hemodynamic intervention to improve postoperative outcomes in moderate and highrisk surgical patients. Anesth Analg 2011;112:1392-402. https://doi. org/10.1213/ANE.0b013e3181eeaae5

15. Pearse R, Dawson D, Fawcett J, Rhodes A, Grounds RM, Bennett $E D$. Early goal-directed therapy after major surgery reduces complications and duration of hospital stay. A randomised, controlled trial. Crit Care 2005;9:R687-93. https://doi.org/10.1186/cc3887

16. Arnold RC, Dellinger RP, Parrillo JE, Chansky ME, Lotano VE, McCoy JV, Jones AE, Shapiro NI, Hollenberg SM, Trzeciak S. Discordance between microcirculatory alterations and arterial pressure in patients with hemodynamic instability. J Crit Care. 2012 Oct;27(5):531.e1-7. https://doi.org/10.1016/j.jcrc.2012.02.007

17. Carsetti A, Watson X, Cecconi M. Haemodynamic coherence in perioperative setting. Best Pract Res Clin Anaesthesiol. 2016 Dec;30(4):445-452. https://doi.org/10.1016/j.bpa.2016.10.007

18. Naumann, D.N., Lima, A. Could resuscitation be based on microcirculation data? No.Intensive Care Med 44, 947-949 (2018). https://doi.org/10.1007/s00134-018-5095-y

19. Rozental O, Thalappillil R, White RS, Tam CW. To Swan or Not to Swan: Indications, Alternatives, and Future Directions. J Cardiothorac Vasc Anesth. 2021 Feb;35(2):600-615. https://doi. org/10.1053/j.jvca.2020.07.067

20. Sarkar M, Umbarkar S. Pulmonary artery catheter - Dilemma is still on? Ann Card Anaesth 2021;24:1-3. https://doi.org/10.4103/ aca.ACA_185_19

21. Van Beest $P$, Wietasch $G$, Scheeren $T$, Spronk $P$, Kuiper $M$. Clinical review: use of venous oxygen saturations as a goal a yet unfinished puzzle. Crit Care. 2011;15(5):232. https://doi. org/10.1186/cc10351

22. Riva JA, Bouchacourt JP, Kohn. The changes in the oxygen saturations in the superior vena cava and the pulmonary artery are not the same during cardiac surgery. Riva JA, Bouchacourt JP, Kohn WE, Hurtado FJ. Rev Esp Anestesiol Reanim. 2015 Mar;62(3):140-4. https://doi.org/10.1016/j.redare.2014.03.002

23. Bouchacourt JP, Kohn E, Riva J, Hurtado FJ. coronary sinus axigen saturation as a determinant of the gradient between superiro vena cava and mixed venus oxigen saturation. Bouchacourt J P, Kohn E, Riva J y Hurtado FJ. Minerva Anestesiol 2011;77(6):57984.

24. Perz S, Uhlig T, Kohl M, Bredle D, Reinhart K, Bauer K, et al. Low and «supranormal» central venous oxygen saturation and markers of tissue hypoxia in cardiac surgery patients: A prospective observational study. Intensive Care Med. 2011;37:52-9. https:// doi.org/10.1007/s00134-010-1980-8

25. Seheult J, Fitzpatrick G, Boran G. Lactic acidosis: an update. Jansen Seheult, Gerard Fitzpatrick and Gerard Boran. Clin Chem Lab Med 2017; 55(3): 322-333 https://doi.org/10.1515/cclm-20160438

26. Haas SA, Lange T, Saugel B, Petzoldt M, Fuhrmann V, Metschke $M$, et al. Severe hyperlactatemia, lactate clearance and mortality in unselected critically ill patients. Intensive Care Med. 2016;42:202-10. https://doi.org/10.1007/s00134-015-4127-0

27. Ranucci $M$, De Toffol $B$, Isgrò $G$, Romitti F, Conti D, Vicentini $M$. Hyperlactatemia during cardiopulmonary bypass: determinants and impact on postoperative outcome. Crit Care. 2006;10(6):R167. https://doi.org/10.1186/cc5113

28. Inoue $\mathrm{S}$, Kuro $\mathrm{M}$, Furuya $\mathrm{H}$. What factors are associated with hyperlactatemia after cardiac surgery characterized by wellmaintained oxygen delivery and a normal postoperative course? A retrospective study. Eur J Anaesthesiol. 2001 Sep;18(9):576-84. https://doi.org/10.1097/00003643-200109000-00004

29. Minton J, Sidebotham DA. Hyperlactatemia and Cardiac Surgery. J Extra Corpor Technol. 2017 Mar;49(1):7-15.

30. Naik R, George G, Karuppiah S, Philip MA. Hyperlactatemia in patients undergoing adult cardiac surgery under cardiopulmonary bypass: Causative factors and its effect on surgical outcome. Ann Card Anaesth. 2016 Oct-Dec;19(4):668-675. https://doi. org/10.4103/0971-9784.191579

31. Demers P, Elkouri S, Martineau R, Couturier A, Cartier R. Outcome with high blood lactate levels during cardiopulmonary bypass in adult cardiac operation. Ann Thorac Surg. 2000 Dec;70(6):2082-6. https://doi.org/10.1016/\$00034975(00)02160-3

32. Hu BY, Laine GA, Wang S, Solis RT. Combined central venous oxygen saturation and lactate as markers of occult hypoperfusion and outcome following cardiac surgery. J Cardiothorac Vasc Anesth. 2012 Feb;26(1):52-7. https://doi.org/10.1053/j. jvca.2011.07.021

33. Mallat J. Use of venous-to-arterial carbon dioxide tension difference to guide resuscitation therapy in septic shock. World J Crit Care Med. 2016;5(1):47. https://doi.org/10.5492/wjccm. v5.i1.47

34. Lamsfus-Prieto J, de Castro-Fernández R, Hernández-García AM, Marcano-Rodriguez $\mathrm{G}$. Valor pronóstico de los parámetros gasométricos del dióxido de carbono en pacientes con sepsis. Una revisión bibliográfica. Rev Esp Anestesiol Reanim. 2016;63(4):22030. https://doi.org/10.1016/j.redar.2015.11.005

35. U W, Long $Y$, Wang $X$, Liu $D$. The Use of the Ratio between the Veno-arterial Carbon Dioxide Difference and the Arterial-venous Oxygen Difference to Guide Resuscitation in Cardiac Surgery Patients with Hyperlactatemia and Normal Central Venous Oxygen Saturation. Chin Med J (Engl). 2015;128(10):1306-13. https://doi. org/10.4103/0366-6999.156770

36. Abou-Arab O, Braik R, Huette P, Bouhemad B, Lorne E, Guinot $\mathrm{P}-\mathrm{G}$. The ratios of central venous to arterial carbon dioxide content and tension to arteriovenous oxygen content are not associated with overall anaerobic metabolism in postoperative cardiac surgery patients. PLoS One. 2018;13(10):1-11. https://doi. org/10.1371/journal.pone.0205950

37. Illescas L, Kohn E, Cavalleri F, Hurtado J, Riva J. Utilidad de las medidas derivadas de la $\mathrm{PO} 2$ en pacientes adultos sometidos cirugía cardíaca con circulación extracorporea. Rev.Chil. anest 2019;48:412-426 https://doi.org/10.25237/revchilanes- 
tv48n05.06

38. Prestes I, Riva J, Bouchacourt JP, Kohn E, López A, Hurtado FJ. Microcirculatory changes during cardiac surgery with cardiopulmonary bypass. Rev Esp Anestesiol Reanim. 2016;63(9):513-8. https://doi.org/10.1016/j.redar.2016.03.005

39. den Os, M.M., van den Brom, C.E., van Leeuwen, A.L.I. et al. Microcirculatory perfusion disturbances following cardiopulmonary bypass: a systematic review. Crit Care 24, 218 (2020) https://doi. org/10.1186/s13054-020-02948-w

40. Dobbe JG, Streekstra GJ, Atasever B, van Zijderveld R, Ince C. Measurement of functional microcirculatory geometry and velocity distributions using automated image analysis. Med Biol Eng Comput. 2008;46(7):659-670. https://doi.org/10.1007/s11517008-0349-4

41. Dubin A, Kanoore Edul VS, Caminos Eguillor JF, Ferrara G. Monitoring Microcirculation: Utility and Barriers - A Point-of-View Review. Vasc Health Risk Manag. 2020 Dec 31;16:577-589. https://doi.org/10.2147NHRM.S242635

42. Biedrzycka A, Lango R. Tissue oximetry in anaesthesia and intensive care. Anaesthesiology Intensive Therapy. 2016;48(1). https:// doi.org/10.5603/AIT.2016.0005

43. Smith RS, Murkin JM. A novel assessment of peripheral tis- sue microcirculatory vasoreactivity using vascular occlusion testing during cardiopulmonary bypass. J Cardiothorac Vasc Anesth. 2014;28(5):1217-1220. https://doi.org/10.1053/j. jvca.2014.03.016

44. Mayeur C, Campard S, Richard C, Teboul JL. Comparison of four different vascular occlusion tests for assessing reactive hyperemia using near-infrared spectroscopy. Crit Care Med. 2011 Apr;39(4):695-701. https://doi.org/10.1097/ CCM.0b013e318206d256

45. Lipcsey M, Eastwood GM, Woinarski NC, Bellomo R. Near-infrared spectroscopy of the thenar eminence: comparison of dynamic testing protocols. Crit Care Resusc. 2012 Jun;14(2):142-7. https://doi.org/10.1186/2110-5820-2-11

46. Vandenbulcke L, Lapage KG, Vanderstraeten KV, De Somer FM, De Hert SG, Moerman AT. Microvascular reactivity monitored with near-infrared spectroscopy is impaired after induction of anaesthesia in cardiac surgery patients: An observational study. Eur J Anaesthesiol. 2017 Oct;34(10):688-694. https://doi. org/10.1097/EJA.0000000000000684

47. Koch $M$, De Backer D, Vincent JL, et al. Effects of propofol on human microcirculation. Br J Anaesth 2008; 101:473-478. https:// doi.org/10.1093/bja/aen210 